\title{
Why Archibald Cochrane used to call for effectiveness and efficiency?
}

I $t$ is reasonable to say that medical care and health practice are in crisis worldwide. For some, this crisis is bad and for others it provides an opportunity of change. We hope that the possible changes will be for the better.

For developing countries, the current process of decision making is even more dramatic, and faced with the opportunities for change one must not be misled by wrong concepts. Traditionally, the medical system in Brazil works looking towards the USA and turning its back on its own reality. With a budget of US $\$ 18$ billion per year, it persists in making the mistake of trying to reproduce the American model, which spends US\$ 1.25 trillion per year.

Moreover, the Brazilian health insurance companies are importing the model of managed care, with has not really been successful in the USA. As is well known, managed care has some good aspects, such as when it emphasizes the importance of the general practitioner (gate keeper) and uses information for the decision-making process obtained from the best existing evidence, and it has some very bad aspects such as when it cuts the freedom of medical decision-making and puts profits ahead of patient's interests.

Unfortunately, some health professionals are confusing evidence-based medicine, which is devoted to the deeper interests of patients and physicians, with the

\footnotetext{
* $M D, P h D, M C E$

Chairman, Department of Internal Medicine, Escola

Paulista de Medicina, Editor, São Paulo Medical Journal.
}

managed care system, which is devoted to the business of making profits.

Evidence-based medicine has the following features: the explicit search for the best evidence, judged honestly (for patient's sake), complemented by the patient's participation in the decision-making, and experience being fine-tuned with practice. This approach is of interest to the doctor or health professional because it reduces theirs chances of making mistakes, and to the patient receiving the benefit, who is given the chance to participate in the decision process involving his life, and certainly of interest to the one who is paying for the process. The payer may be the Brazilian SUS (Unified Health System), the health insurance companies, or the patient as a private individual or as a taxpayer.

So, confusing managed care with evidence-based medicine is the same as keeping the bath water while throwing the baby away. I hope that ignorance will not lead us to make the wrong decisions at this crucial moment. For instance, when we decide to treat 100 patients with myocardial infarction we may spend U\$ 20,000 using streptokinase to save 3 lives, or use RTPA and spend U\$ 200,000. Thus, there is a difference of U\$ 180,000 between the two approaches. Whoever is interested in profit may take the money and run away or expand his business; whoever is interested in saving lives may use the U\$ 180,000 to treat another 900 patients and save another 27 lives. I think this latter is the case for developing countries and evidence-base medicine.

Archibald Cochrane, one of the most influential epidemiologists of this century, used to call for effectiveness and efficiency in medicine, aiming social justice and equality. It is important not to miss this point. 